\title{
An Asymptomatic Hemorrhagic Hepatic Cyst with Solid Contents
}

\author{
Ryota Kondo $^{1}$, Hiroshi Yoshida ${ }^{{ }^{*}}$, Atsushi Hirakata ${ }^{1}$, Hiroshi Makino ${ }^{1}$, Tadashi Yokoyama ${ }^{1}$, Hiroshi Maruyama ${ }^{1}$, Masahiro \\ Hotta $^{1}$, Junji Ueda ${ }^{1}$, Yasuhiro Mamada ${ }^{2}$, Nobuhiko Taniai ${ }^{2}$ and Eiji Uchida ${ }^{2}$ \\ ${ }^{1}$ Department of Surgery, Nippon Medical School Tama Nagayama Hospital, 1-7-1 Nagayama, Tama-city, Tokyo, 206-8512, Japan \\ ${ }^{2}$ Department of Surgery, Nippon Medical School, 1-7-1 Nagayama, Tama-city, Tokyo, 206-8512, Japan
}

\begin{abstract}
We describe a patient who had an asymptomatic hemorrhagic hepatic cyst with solid contents that mimicked a malignancy. An 85-year-old woman was referred to our hospital because a hypoechoic mass was detected. She had no complications. The past medical history included hypertension and left femoral artery aneurysm. The results of initial laboratory tests were as follows: serum aspartate aminotransferase, $28 \mathrm{IU} / \mathrm{L}$; serum alanine aminotransferase, $23 \mathrm{IU} / \mathrm{L}$; serum C-reactive protein, $0.11 \mathrm{mg} / \mathrm{dL}$; and serum hemoglobin concentration, $13.1 \mathrm{~g} / \mathrm{dL}$. The serum platelet count $(17.3 \times 104 / \mu \mathrm{L})$ was slightly decreased. The serum concentration of carcinoembryonic antigen was $3.0 \mathrm{ng} / \mathrm{mL}$, that of CA19-9 was $12.2 \mathrm{u} / \mathrm{ml}$, and that of AFP was $3.8 \mathrm{ng} / \mathrm{ml}$. The serum concentration of hyaluronic acid $(147 \mathrm{ng} / \mathrm{mL})$ was elevated. Hepatitis $B$ virus antigen and hepatitis $C$ virus antibody were negative. Ultrasonography revealed a protruding hypoechoic mass, $6 \mathrm{~cm}$ in diameter, with a central isoechoic structure in segment 7 , accompanied by multiple hepatic cysts. The edge of the liver was dull, and the liver parenchymal echo was mildly rough. Computed tomography (CT) showed a slightly high-density area with calcification of the margin. Magnetic resonance imaging revealed a hypointense lesion with central hyperintensity on T1weighted sequences and hyperintensity on T2-weighted sequences. On positron emission tomography$\mathrm{CT}$, there was no uptake of fluorodeoxyglucose in the liver. We diagnosed an old hemorrhagic cyst or abscess, but could not rule out a malignant neoplasm because of the damaged liver. A right lateral sectionectomy was therefore performed. The resected specimen had black solid contents, and the capsule lacked fluid. Pathological examination revealed an old hemorrhage with a thick fibrous capsule without epithelial components. The liver showed mild fibrosis with fatty changes. The lesion was considered an old hemorrhagic hepatic cyst because a nearby hepatic cyst had simple columnar epithelium.
\end{abstract}

\section{Publication History:}

Received: October 31, 2014

Accepted: December 16, 2014

Published: December 18, 2014

\section{Keywords:}

Hemorrhagic hepatic cyst, Solid content, Multiple hepatic cysts, Liver

\section{Introduction}

Simple hepatic cysts are benign cystic formations that occur frequently in the general population, with a prevalence ranging from $2 \%$ to $4 \%$ [1-3]. Most benign, nonparasitic hepatic cysts are found incidentally and are usually asymptomatic. However, complications such as obstructive jaundice [4], rupture [5-9], intracystic hemorrhage [9-15], and infection [16-24] can occasionally occur. Most patients with a hemorrhagic hepatic cyst present with abdominal pain (80\%), while some cases are asymptomatic at the time of presentation [15].

Malignant neoplasms occasionally present in damaged liver Intracystic hemorrhage and cystadenocarcinoma of the liver sometimes cannot be reliably differentiated on imaging studies. Even when diagnosed accurately, the optimal treatment strategy remains controversial. Hepatectomy is usually performed in this situation $[9,11]$.

We describe a patient who had an asymptomatic hemorrhagic hepatic cyst with solid contents that mimicked a malignancy.

\section{Case Report}

An 85-year-old woman was referred to our hospital because a hypoechoic mass was detected in the liver on physical examination. The patient had no complications. Her past medical history included hypertension and a left femoral-artery aneurysm. She did not have a bleeding tendency and was not receiving antiplatelet agents or anticoagulant agents.

The results of initial laboratory tests were as follows: serum aspartate aminotransferase, $28 \mathrm{IU} / \mathrm{L}$ (normal, <28 IU/L); serum alanine aminotransferase, $23 \mathrm{IU} / \mathrm{L}$ (normal, <33 IU/L); serum lactic dehydrogenase, $238 \mathrm{IU} / \mathrm{L}$ (normal, 180 to $460 \mathrm{IU} / \mathrm{L}$ ); serum gamma glutamic transpeptidase, $20 \mathrm{IU} / \mathrm{L}$ (normal, 8 to $39 \mathrm{IU} / \mathrm{L}$ ); serum albumin, $4.0 \mathrm{~g} / \mathrm{dL}$ (normal, 3.8 to $5.3 \mathrm{~g} / \mathrm{dL}$ ); serum C-reactive protein, $0.11 \mathrm{mg} / \mathrm{dL}$ (normal, $<0.3 \mathrm{mg} / \mathrm{dL}$ ); white blood cell count, $5600 / \mu \mathrm{L}$ (normal, 4000 to $8000 / \mu \mathrm{L}$ ); red blood cell count, $407 \times 104 / \mu \mathrm{L}$ (normal, 410 to $550 \times 104 / \mu \mathrm{L}$ ); and serum hemoglobin concentration, $13.1 \mathrm{~g} /$ $\mathrm{dL}$ (normal, 14 to $18 \mathrm{~g} / \mathrm{dL}$ ). The serum platelet count was $17.3 \times 104 /$ $\mu \mathrm{L}$ (normal, 20 to $40 \times 104 / \mu \mathrm{L}$ ) and was thus slightly decreased. The prothrombin time was $127.6 \%$ (normal, $70 \%$ to $130 \%$ ), and the activated partial thromboplastin time was $26.0 \mathrm{~s}$ (normal, 24 to $37 \mathrm{~s}$ ). The serum concentration of carcinoembryonic antigen was $3.0 \mathrm{ng} / \mathrm{mL}$ (normal $<2.5 \mathrm{ng} / \mathrm{mL}$ ), that of CA19-9 was $12.2 \mathrm{u} / \mathrm{ml}$ (normal $<37$ ), and that of AFP was $3.8 \mathrm{ng} / \mathrm{ml}$ (normal $<10$ ). The serum concentration of hyaluronic acid $(147 \mathrm{ng} / \mathrm{mL}$ ) was elevated (normal $<50 \mathrm{ng} / \mathrm{mL}$ ). Hepatitis $B$ virus antigen and hepatitis $C$ virus antibody were negative.

Ultrasonography revealed a protruding hypoechoic mass, $6 \mathrm{~cm}$ in diameter, with a central isoechoic structure in segment 7 , accompanied by multiple hepatic cysts. On Doppler ultrasonography, no blood flow was detected in the hypoechoic mass. The edge of the liver was dull,

"Corresponding Author: Dr. Hiroshi Yoshida, Department of Surgery, Nippon Medical School Tama Nagayama Hospital, 1-7-1 Nagayama, Tama-city, Tokyo, 206-8512, Japan, Tel: +81-42-371-2111, Fax: +81-42-372-7306; E-mail: hiroshiy@nms.ac.jp

Citation: Kondo R, Yoshida H, Hirakata A, Makino H, Yokoyama T, et al. (2014)An Asymptomatic Hemorrhagic Hepatic Cyst with Solid Contents. Int J Gastroentero Disord Ther 1: 110. doi: http://dx.doi.org/10.15344/2393-8498/2014/110

Copyright: (c) 2014 Kondo et al. This is an open-access article distributed under the terms of the Creative Commons Attribution License, which permits unrestricted use, distribution, and reproduction in any medium, provided the original author and source are credited. 
Kondo R, Yoshida H, Hirakata A, Makino H, Yokoyama T, et al. (2014) An Asymptomatic Hemorrhagic Hepatic Cyst with Solid Contents. Int J Gastroenterol Disord Ther 1: 110. doi: http://dx.doi.org/10.15344/2393-8498/2014/110

and the liver parenchymal echo was mildly rough (Figure 1).

Computed tomography (CT) showed a slightly high-density area with calcification of the margin as compared with that of the other hepatic cysts (Figure 2). Magnetic resonance imaging (MRI) revealed a hypointense lesion with central hyperintensity on T1-weighted sequences and hyperintensity on T2-weighted sequences (Figure 3). On positron emission tomography (PET)-CT, there was no uptake of fluorodeoxyglucose (FDG) in the liver (Figure 4).

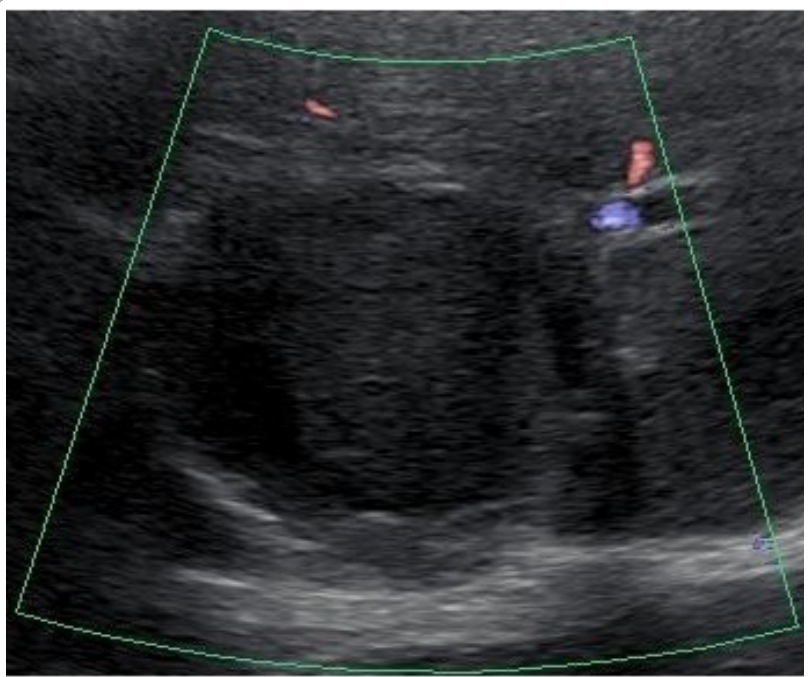

Figure 1: Ultrasonography revealed a protruding hypoechoic mass, $6 \mathrm{~cm}$ in diameter, with a central isoechoic structure in segment 7 , accompanied by multiple hepatic cysts. On Doppler ultrasonography, no blood flow was detected in the hypoechoic mass.

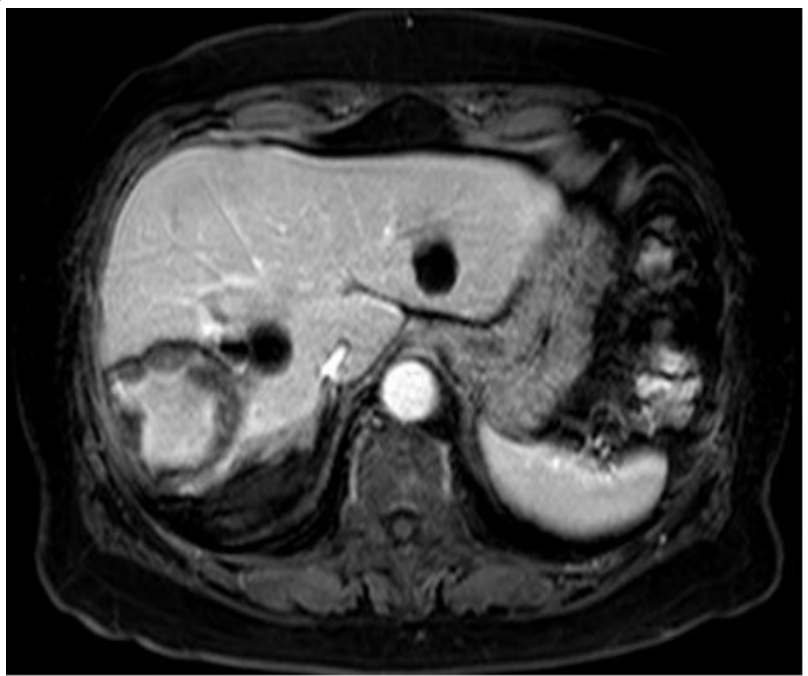

Figure 2: Computed tomography showed a slightly high-density area with calcification of the margin as compared with that of the other hepatic cysts.

We diagnosed an old hemorrhagic cyst or abscess, but could not rule out a malignant neoplasm because of the damaged liver. After obtaining informed consent, a laparotomy was performed. The mass protruded from the liver, and adhesion to right diaphragm was detected (Figure 5). A right lateral sectionectomy was performed. The resected specimen had black solid contents, and the capsule fluid
(Figure 6). Pathological examination revealed an old hemorrhage with a thick fibrous capsule without epithelial components. The liver showed mild fibrosis with fatty changes. The mass was considered an old hemorrhagic hepatic cyst because a nearby hepatic cyst had simple columnar epithelium (Figure 7). The postoperative course was uneventful, and the patient was discharged 8 days after operation.

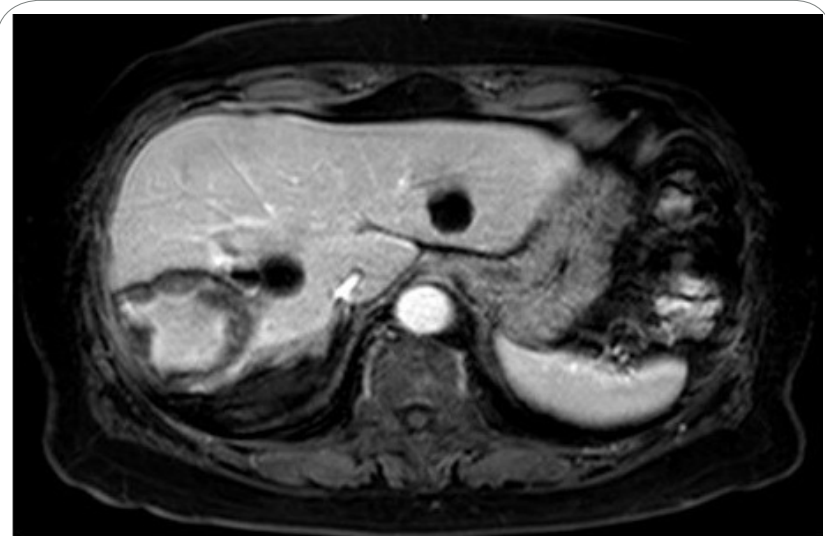

Figure 3: Magnetic resonance imaging revealed a hypointense lesion with central hyperintensity on T1-weighted sequences (a) and hyperintensity on T2-weighted sequences (b).

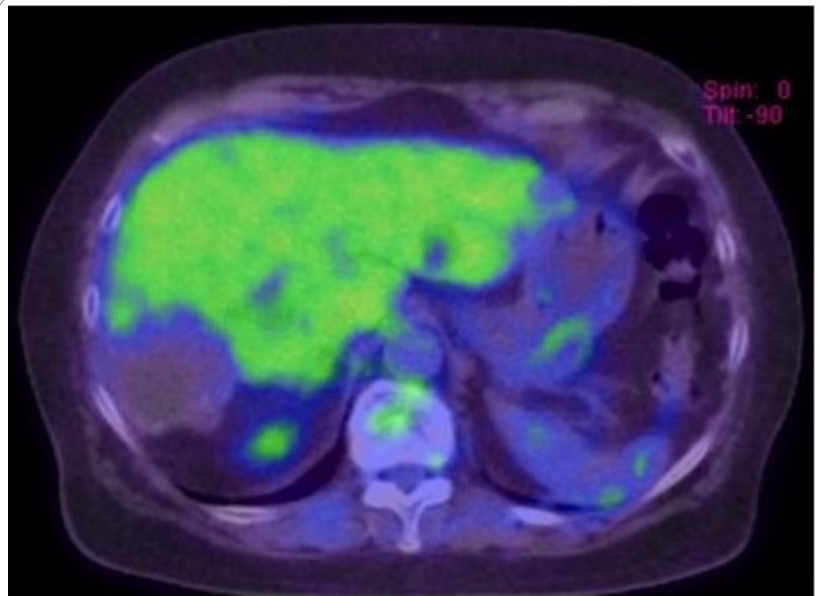

Figure 4: On positron emission tomography-CT, there was no uptake of fluorodeoxyglucose in the liver.

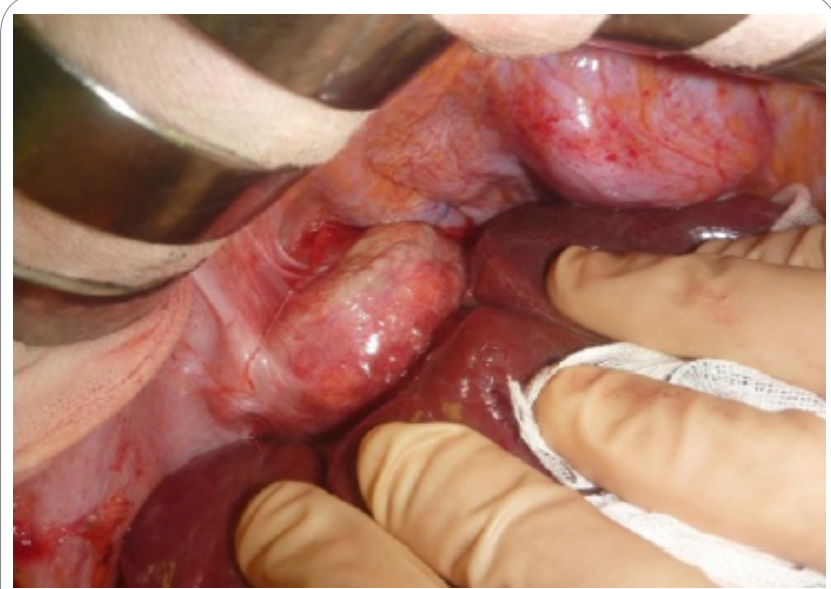

Figure 5: The mass protruded from the liver and adhered to the right diaphragm.
Int J Gastroenterol Disord Ther ISSN: $2393-849$
IJGDT, an open access journal Volume 1. 2014. 110 


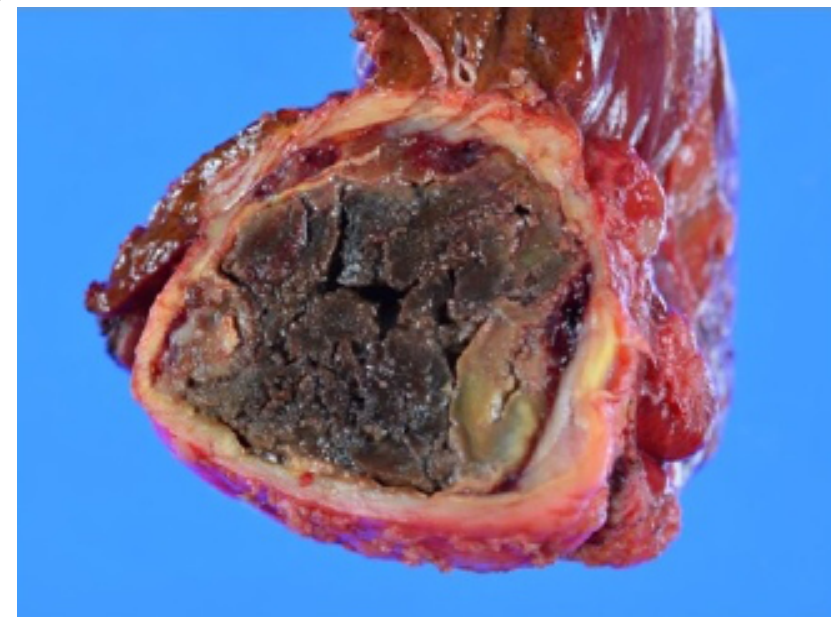

Figure 6: A right lateral sectionectomy was performed. The resected specimen had black solid contents, and the capsule lacked fluid.

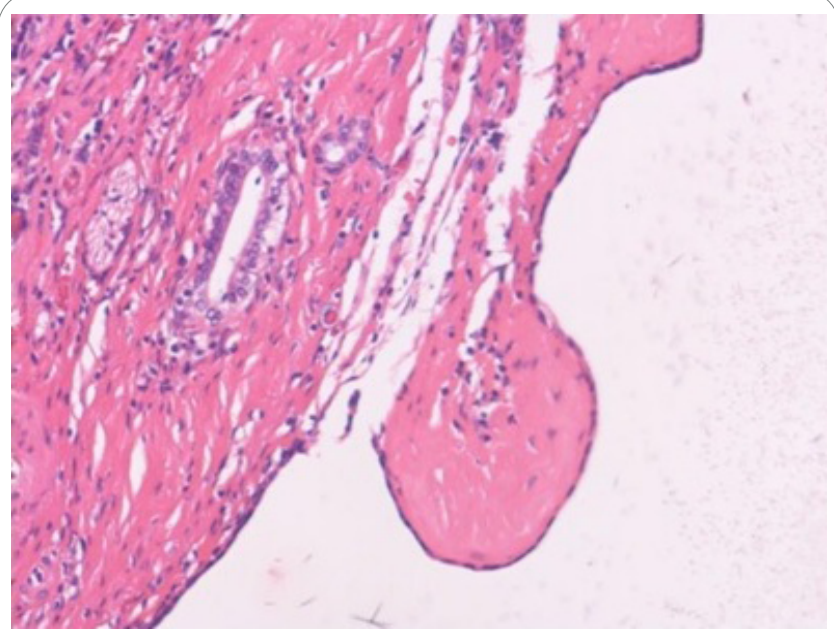

Figure 7: Pathological examination revealed an old hemorrhage with a thick fibrous capsule without epithelial components. The liver showed mild fibrosis with fatty changes. The mass was considered an old hemorrhagic hepatic cyst because a nearby hepatic cyst had simple columnar epithelium.

Simple hepatic cysts can be congenital or acquired and occur more frequently in females and elderly patients. They are common and benign, usually asymptomatic, and require no treatment $[15,25]$. They occasionally resolve spontaneously, but can also cause serious complications [4-14,16-23,26]. Fong et al. reviewed the literature on hemorrhagic hepatic cysts [27]. The mean age was 62.7 years, and the mean size of the cyst was $11.2 \mathrm{~cm}$. Most patients with hemorrhagic cysts presented with abdominal pain (80\%), while $14 \%$ of the patients were asymptomatic at presentation. Treatment recommendations for symptomatic hepatic cysts include surgery [28-30] and the injection of a sclerosing agent into the cyst [31-33]. The clinical presentation of spontaneous intracystic hemorrhage usually begins with severe abdominal pain of sudden onset, followed by a gradual decline in pain and healing in response to conservative

\section{Discussion}

therapy $[10,12,13,34]$. In our patient, the cyst was asymptomatic at the time of presentation. However, Marion et al. [35] reported a case of hemorrhagic hepatic cyst rupture that presented with hemorrhagic shock.

In most cases, the causes of intracystic hemorrhage are unclear. The wall of a hepatic cyst consists of three layers: an inner layer of loose connective tissue lined with cylindrical or cuboidal epithelium, a middle layer of compact connective tissue containing blood vessels, and an outer layer of loose connective tissue with large blood vessels, bile ducts, and occasional von Meyenburg complexes. On exposure to high intracystic pressure, the epithelial lining may undergo necrosis and sloughing. In our patient, the presence of calcification of the cystic wall suggested that sclerosis of the blood vessels in the cyst wall may have caused the intracystic hemorrhage [36]. Hemorrhage might occur repeatedly, gradually contributing to the size of the cyst.

On ultrasonography, hemorrhagic hepatic cysts typically contain fluid that is hyperechogenic as compared with that in simple cysts. On MRI, intracystic hemorrhage is frequently associated with internal signal intensities. Hyperintensity on T1- and T2-weighted MRI sequences can help to differentiate intracystic hemorrhage from other cystic lesions. On T1-weighted images, the signal intensity of fluid changes from low to high as the protein concentration increases [37]. In our patient, the hemorrhagic cyst was a hypointense mass with central hyperintensity on T1-weighted sequences and hyperintensity on T2-weighted sequences. The signal intensity of hemorrhage decreases when clots are liquefied [38]. Fong et al. reported imaging workup data obtained in 15 patients with hemorrhagic hepatic cysts who underwent a combination of abdominal ultrasonography, CT, and MRI. On T1- and T2-weighted MRI of the abdomen, eight patients (53.3\%) showed hyperintense signals and the other seven (46.7\%) had a mixture of hyperintense and hypointense signals. Of the seven patients with mixed signals, three showed intracystic hyperintense signals surrounded by a rim of hypointensity. The other four patients exhibited hyperintensity with scattered hypointense nodularity [15]. Calcification of the cyst wall may occur, but is also seen in nonhemorrhagic simple cysts. Most cyst walls are thin and smooth and are not enhanced on CT or MRI after intravenous injection of contrast medium. However, enhanced thick walls are occasionally seen in the presence of inflammation, granulation, or fibrosis. After hemorrhage, cyst fluid is usually hyperdense on CT, hyperintense on T1-weighted MR images, and hypointense to hyperintense on T2-weighted images. A fluid-fluid level is sometimes observed.

Differentiating hepatobiliary cystic neoplasms from simple hepatic cysts complicated by intracystic hemorrhage can be difficult because both lesions have intracystic structures [13, 39]. Cytologic examination of cystic fluid obtained by aspiration may provide important information for distinguishing malignant from benign lesions [11]. However, aspiration of a cystic lesion can lead to tumor spread.

We diagnosed an old hemorrhagic cyst or abscess, but could not rule out a malignant neoplasm because of liver damage. A sectionectomy was therefore performed. On macroscopic examination, the resected specimen had black solid contents with a capsule that lacked fluid. Pathological examination revealed an old hemorrhage with a thick fibrous capsule without epithelial components. The mass was considered an old hemorrhagic hepatic cyst because a nearby hepatic cyst had simple columnar epithelium.

Int J Gastroenterol Disord Ther

ISSN: $2393-849$
IJGDT, an open access journal Volume 1. 2014. 110 
Kondo R, Yoshida H, Hirakata A, Makino H, Yokoyama T, et al. (2014) An Asymptomatic Hemorrhagic Hepatic Cyst with Solid Contents. Int J Gastroenterol Disord Ther 1: 110. doi: http://dx.doi.org/10.15344/2393-8498/2014/110

\section{Competing Interests}

The authors declare that they have no competing interests.

\section{Author's contribution}

All authors contributed substantially to conception and design, acquisition and analysis of data and interpretation of results.

\section{References}

1. Gaines PA, Sampson MA (1989) The prevalence and characterization of simple hepatic cysts by ultrasound examination. Br J Radiol 62: 335-337.

2. Redston MS, Wanless IR (1996) The hepatic von Meyenburg complex prevalence and association with hepatic and renal cysts among 2843 autopsies. Mod Pathol 9: 233-237.

3. Caremani M, Vincenti A, Benci A, Sassoli S, Tacconi D (1993) Ecographic epidemiology of non-parasitic hepatic cysts. J Clin Ultrasound 21: 115-118.

4. Schwed DA, Edoga JK, Stein LB (1993) Biliary obstruction due to spontaneous hemorrhage into benign hepatic cyst. J Clin Gastroenterol 16 84-86.

5. Andersson R, Tranberg KG, Bengmark S (1988) Hemoperitoneum after spontaneous rupture of liver tumor: results of surgical treatment. HPB Surg 1: 81-83.

6. Klingler PJ, Bodner E, Schwelberger HG (1998) Late complication after laparoscopic fenestration of a liver cyst. Surg Laparosc Endosc 8: 76-77.

7. Lotz GW, Stahlschmidt M (1989) Intra-abdominal bleeding after rupture of hepatic cyst. South Med J 82: 667.

8. Ueda J, Yoshida H, Taniai N, Mineta S, Kawano Y, et al. (2010) A case of spontaneous rupture of a simple hepatic cyst. J Nippon Med Sch 77 $181-185$

9. Yamaguchi $M$, Kuzume $M$, Matsumoto $T$, Matsumiya $A$, Nakano $H$, et al. (1999) Spontaneous rupture of a nonparasitic liver cyst complicated by intracystic hemorrhage. J Gastroenterol 34: 645-648.

10. Zanen AL, van Tilburg AJ (1995) Bleeding into a liver cyst can be treated conservatively. Eur J Gastroenterol Hepatol 7: 91-93.

11. Hanazaki K, Wakabayashi M, Mori H, Sodeyama H, Yoshizawa K, et al (1997) Hemorrhage into a simple liver cyst: diagnostic implications of a recent case. J Gastroenterol 32: 848-851.

12. Yoshida H, Onda M, Tajiri T, Mamada $Y$, Taniai N, et al. (2002) Intracystic hemorrhage of a simple hepatic cyst. Hepatogastroenterology 49: 10951097.

13. Takahashi G, Yoshida H, Mamada Y, Taniai N, Bando K, et al. (2008) Intracystic hemorrhage of a large simple hepatic cyst. J Nippon Med Sch 75: 302-305.

14. Kawano $\mathrm{Y}$, Yoshida H, Mamada $\mathrm{Y}$, Taniai N, Mineta S, et al. (2011) Intracystic hemorrhage required no treatment from one of multiple hepatic cysts. J Nippon Med Sch 78: 312-316.

15. Fong ZV, Wolf AM, Doria C, Berger AC, Rosato EL, et al. (2012) Hemorrhagic hepatic cyst: report of a case and review of the literature with emphasis on clinical approach and management. J Gastrointest Surg 16 1782-1789.

16. Yoshida H, Onda M, Tajiri T, Mamada Y, Taniai N, et al. (2003) Infected hepatic cyst. Hepatogastroenterology 50: 507-509.

17. Yoshida H, Tajiri T, Mamada Y, Taniai N, Kawano Y, et al. (2003) Infected solitary hepatic cyst. J Nippon Med Sch 70: 515-518.

18. Quigley M, Joglekar VM, Keating J, Jagath S (2003) Fatal Clostridium perfringens infection of a liver cyst. J Infect 47: 248-250.

19. Egbuna O, Johnson S, Pavlakis M (2007) Rupture of an infected liver cyst into the pericardium in a kidney transplant recipient with polycystic kidney disease. Am J Kidney Dis 49: 851-853.

20. Keven K, Bengisun JS, AltuntaÅŸ F, Akar H, NergizoÄŸlu G, et al. (2001) Cystic infection of the liver in a maintenance haemodialysis patient. Nephro Dial Transplant 16: 859-860.
21. Eloubeidi MA, Rockey DC (2000) Infected hepatic cyst masquerading as abdominal aortic aneurysm. Dig Dis Sci 45: 1977-1980.

22. Bourgeois $N$, Kinnaert $P$, Vereerstraeten $P$, Schoutens $A$, Toussaint C (1983) Infection of hepatic cysts following kidney transplantation in polycystic disease. World J Surg 7: 629-631.

23. Shoji F, Kitamura M, Shirabe K, Kai H, Akiyoshi T, et al. (2000) Infected hepatic cyst in a patient with multiple hepatic cysts: report of a case diagnosed by change of ultrasonographic findings. Eur $\mathrm{J}$ Gastroenterol Hepatol 12: 703-705.

24. Ishii K, Yoshida H, Taniai N, Moneta S, Kawano Y, et al. (2009) Infected hepatic cyst treated with percutaneous transhepatic drainage. J Nippon Med Sch 76: 160-164.

25. Ammori BJ, Jenkins BL, Lim PC, Prasad KR, Pollard SG, et al. (2002) Surgical strategy for cystic diseases of the liver in a western hepatobiliary center. World J Surg 26: 462-469.

26. Yoshida H, Onda M, Tajiri T, Mamada Y, Taniai N, et al. (2001) Spontaneous disappearance of a hepatic cyst. J Nippon Med Sch 68: 58-60.

27. Yoon SS, Charny CK, Fong Y, Jarnagin WR, Schwartz LH, et al. (2003) Diagnosis, management, and outcomes of 115 patients with hepatic hemangioma. J Am Coll Surg 197: 392-402.

28. Jones WL, Mountain JC, Warren KW (1974) Symptomatic non-parasitic cysts of the liver. Br J Surg 61: 118-123.

29. Diez J, Decoud J, Gutierrez L, Suhl A, Merello J (1998) Laparoscopic treatment of symptomatic cysts of the liver. Br J Surg 85: 25-27. Klingler PJ, Gadenstätter M, Schmid T, Bodner E, Schwelberger HG (1997) Treatment of hepatic cysts in the era of laparoscopic surgery. Br J Surg 84: 438-444.

30. Klingler PJ, Gadenstätter M, Schmid T, Bodner E, Schwelberger HG (1997) Treatment of hepatic cysts in the era of laparoscopic surgery. $\mathrm{Br} \mathrm{J}$ Surg 84: 438-444.

31. Yoshida H, Egami K, Onda M, Tajiri T, Uchida E (1996) Treatment of symptomatic hepatic cyst by injection of minocycline hydrochloride. $\mathrm{J}$ Hepatobiliary Pancreat Surg 3: 491-494.

32. Yoshida H, Onda M, Tajiri T, Arima Y, Mamada Y, et al. (2003) Long-term results of multiple minocycline hydrochloride injections for the treatment of symptomatic solitary hepatic cyst. J Gastroenterol Hepatol 18: 595-598.

33. Bean WJ, Rodan BA (1985) Hepatic cysts: treatment with alcohol. AJR Am J Roentgenol 144: 237-241.

34. Chang SS, Chan CC, Wang SS, Chang FY, Lee SD (2000) Repeated episodes of spontaneous intracystic hemorrhage of hepatic cysts mimicking malignancy. Zhonghua Yi Xue Za Zhi (Taipei) 63: 256-261.

35. Marion Y, Brevartt C, Plard L, Chiche L (2013) Hemorrhagic liver cys rupture: an unusual life-threatening complication of hepatic cyst and literature review. Ann Hepatol 12: 336-339.

36. GAVISER D (1953) Solitary nonparasitic cysts of the liver. Minn Med 36: 831-836.

37. Vilgrain V, Silbermann O, Benhamou JP, Nahum H (1993) MR imaging in intracystic hemorrhage of simple hepatic cysts. Abdom Imaging 18: 164167.

38. Gomori JM, Grossman RI (1987) Head and neck hemorrhage. Magn Reson Annu.

39. Horsmans Y, Laka A, Gigot JF, Geubel AP (1996) Serum and cystic fluid CA 19-9 determinations as a diagnostic help in liver cysts of uncertain nature. Liver 16: 255-257. 